\title{
Intestinal parasitic infestation and anaemic status among the adolescent boys in Bangladesh
}

\section{Md. Hafiz Uddin ${ }^{1}$ and Hamida Khanum}

Department of Zoology, University of Dhaka, Dhaka-1000, Bangladesh

${ }^{1}$ Laboratory Sciences Division, ICDDR, B, Mohakhali, Dhaka-1212, Bangladesh

\begin{abstract}
The prevalence of intestinal parasitic infestation and anaemic status of adolescent boys (age 10-19 years) of two selected villages, Kutumbopur, Comilla and Gazirchat, Dhaka districts was investigated. Anaemic status was determined by measuring hemoglobin percentage and parasitic infestation was detected and identified under microscope with wet mount and stained preparations. Out of 106 adolescent boys, only two $(1.9 \%)$ showed severe anaemia. Among the other anaemic status, 50.9\% was moderately anaemic, $39.6 \%$ mildly anaemic and 7.5\% non anaemic. Adolescent boys were infected $(49.01 \%)$ with one or more type of protozoan and helminth parasites. Both anaemia and parasitic infestation were more prevalent in Gazirchat while compared to Kutumbopur. Parasitic infestation and anaemia was not correlated.
\end{abstract}

Key words: Anaemia, adolescent boys, Ascaris, Trichuris, Entamoeba, Giardia

\section{Introduction}

Anaemia is a common health problem with public health importance, affecting millions of people throughout the world. It is one of the most common problem in the developing countries like Bangladesh. Anaemia can be defined as a reduction of hemoglobin concentration per unit volume of peripheral blood below the normal (WHO, 1992). Hemoglobin concentration which is below $95 \%$ confidence interval for healthy, well nourished individuals of same age, sex and stage of pregnancy recognized as anaemic (Gilgen, 1998). The most common cause of anaemia are deficiency of iron, mal-nutrition and parasitic infestation. On the other hand, intestinal parasites in Bangladesh producing detrimental effects to health of million of people mainly children and adolescents (Karim et al., 1998).

Adolescent boys are at high risk to gain parasitic infection because of their behavioural aspects, general hygiene knowledge, socio-economic status, etc. The present study aimed to determine the prevalence of intestinal infection among the adolescent boys and its effect on the anaemic status.

\section{Materials and Methods}

The present study was conducted on 106 adolescent boys, between 10 to the age of 19 years of age of two selected areas, Kutumbopur of Comilla district, a rural village whereas Gazirchat of Dhaka district, a peri urban village. The study was carried out from January to June 2002. Blood and stool samples were collected from the boys to determine the hemoglobin level and parasitic infestation respectively.
Blood sample was taken from the finger tip with pricking needle and hemoglobin concentration was measured instantly in the field with sahli hemoglobinometer according to WHO $(1992,1994)$.

An empty dry plastic container was provided to each of the boys to collect stool in the next morning. If any one failed to collect stool, these were collected through repeated visits. The stool samples were carried to the Parasitology Laboratory, Department of Zoology, University of Dhaka for microscopic examination.

\section{Result and Discussion}

In Kutumbopur 33.82\% individuals were infected with one or more type of parasites. Among them $86.96 \%$ showed single infection and $13.04 \%$ showed infection with two different parasites (Table-1). No triple infection was observed in Kutumbopur. In case of helminth, prevalence of Ascaris lumbricoides, Trichuris trichiura were $29.41 \%$ and $5.9 \%$ respectively. The only protozoan parasite Entamoeba histolytica found in $2.94 \%$ adolescents.

Parasitic infestation was observed much higher in Gazirchat compared to Kutumbopur. Infestation rate was $84.21 \%$, in which single infection observed in $43.75 \%$ cases, double infection observed in $37.25 \%$ cases and triple infection in $18.75 \%$ cases (Table-1). Both A. lumbricoides, T. trichiura showed a prevalence rate of $37.5 \%$. The prevalence of hookworm was $43.75 \%$, Enterobius vermicularis was $18.75 \%$, Diphybothrium latum was $6.25 \%$ and Giardia lamblia was $31.25 \%$.

Table 1. Prevalence of parasitic infestation among the adolescent boys of Kutombopur and Gazirchat villages.

\begin{tabular}{lccccccccc}
\hline \multirow{1}{*}{ Areas } & \multirow{2}{*}{$\begin{array}{c}\text { No. of } \\
\text { boys }\end{array}$} & \multicolumn{2}{c}{ Infection } & \multicolumn{2}{c}{ Single infection } & \multicolumn{2}{c}{ Double infection } & \multicolumn{2}{c}{ Triple infection } \\
\cline { 2 - 10 } & & No & \% & No & \% & No & \% & No & \% \\
\hline Kutumbopur & 68 & 23 & 33.82 & 20 & 86.96 & 3 & 13.04 & 0 & 0 \\
Gazirchat & 38 & 32 & 84.21 & 14 & 43.75 & 12 & 37.50 & 6 & 18.75 \\
Total & 106 & 55 & 51.90 & 34 & 61.81 & 15 & 27.30 & 6 & 10.90 \\
\hline
\end{tabular}


In Kutumbopur, few double infections were observed such as, $A$. lumbricoides and T. trichiura (8.69\%) and A. lumbricoides and E. histolytica (4.35\%). In Gazirchat, double infection was most prevalent such as, A. lumbricoides and T. trichiura; A. lumbricoides and hookworm; hookworm and E. vermicularis; E. vermicularis and $G$. lamblia etc. The infestation rate of T. trichiura with hookworm was $6.25 \%$ in the adolescent boys (Table 2).

Table 2. Double infections among the adolescent boys of Kutombopur and Gazirchat villages.

\begin{tabular}{lcc|cc}
\hline \multicolumn{1}{c}{ Parasites } & \multicolumn{2}{c|}{ Kutumbopur } & \multicolumn{2}{c}{ Gazirchat } \\
\cline { 2 - 5 } & No & \% & No & \% \\
\hline $\begin{array}{l}\text { A. lumbricoides \& } \\
\text { T. trichiura }\end{array}$ & 2 & 8.69 & 4 & 12.5 \\
\hline $\begin{array}{l}\text { A. lumbricoides \& } \\
\text { E. histolytica }\end{array}$ & 1 & 4.35 & 0 & 0 \\
\hline $\begin{array}{l}\text { A. lumbricoides \& } \\
\text { Hookworm }\end{array}$ & 0 & 0 & 2 & 6.25 \\
\hline $\begin{array}{l}\text { E. vermicularis \& } \\
\text { Hookworm }\end{array}$ & 0 & 0 & 1 & 3.12 \\
\hline $\begin{array}{l}\text { E. vermicularis \& } \\
\text { G. lamblia }\end{array}$ & 0 & 0 & 3 & 9.37 \\
\hline $\begin{array}{l}\text { T. trichiura \& } \\
\text { Hookworm }\end{array}$ & 0 & 0 & 2 & 6.25 \\
\hline
\end{tabular}

Triple infections were only prevalent in Gazirchat such as, A. lumbricoides with $T$. trichiura and hookworm; A. lumbricoides with $D$. latum and $G$. lamblia; and $T$. trichiura with hookworm and $G$. lamblia. Each of the triple infection was found in 2 individuals $(6.25 \%)$ of the Gazirchat area.

In Kutumbopur, 91.2\% adolescent boys showed different degree of anaemia, among them $41.2 \%$ was moderately anaemic, 50\% was mildly anaemic and
$8.82 \%$ was non anaemic. No severe case was found in Kutumbopur. On the other hand, in Gazirchat, out of 38 adolescents, $5.26 \%$ was severely anaemic, $68.42 \%$ was moderately anaemic, $21.05 \%$ was mildly anaemic and $5.26 \%$ was non anaemic (Table 3 ).

Table 3. Different anaemic conditions of the adolescent boys of Kutombopur and Gazirchat villages.

\begin{tabular}{lcccccc}
\hline \multirow{2}{*}{ Status of } & \multicolumn{2}{c}{ Kutumbopur } & \multicolumn{2}{c}{ Gazirchat } & \multicolumn{3}{c}{$\begin{array}{c}\text { Kutumbopur+ } \\
\text { Gazirchat }\end{array}$} \\
\cline { 2 - 7 } & No & $\mathbf{9}$ & No & \% & No & \% \\
\hline Severe & 0 & 0 & 2 & 5.26 & 2 & 1.90 \\
Moderate & 28 & 41.2 & 26 & 68.42 & 54 & 50.9 \\
Mild & 34 & 50.0 & 8 & 21.05 & 42 & 39.6 \\
Non & 6 & 8.82 & 2 & 5.26 & 8 & 7.50 \\
anaemic & & & & & & \\
\hline Total & 68 & & 38 & & 106 \\
\hline
\end{tabular}

Parasitic infection and anaemic prevalence both were higher in Gazirchat than in Kutumbopur (Table 4). Highest parasitic infestation $(90.9 \%)$ observed in Gazirchat in the age group 10-12. The anaemic conditions were also prevalent in both the areas in the age groups 10-12 and 12-14 (Table 5). The correlation between anaemia and parasitic infestation was statistically insignificant $\left(\chi^{2}=0.716, p>0.05\right)$

Table 4. Relationship between parasitic infestation and anaemia among the adolescent boys of Kutumbopur and Gazirchat.

\begin{tabular}{lcccc}
\hline Areas & $\begin{array}{l}\text { No. of Infected } \\
\text { boys }\end{array}$ & $\begin{array}{c}\text { Prevalence } \\
\text { of infestation } \\
\text { (\%) }\end{array}$ & $\begin{array}{c}\text { Prevalence of } \\
\text { anaemia } \\
\text { (\%) }\end{array}$ \\
\hline Kutumbopur & 68 & 23 & 33.82 & 91.17 \\
Gazirchat & 38 & 32 & 84.21 & 94.73 \\
\hline Total & 106 & 55 & 51.88 & 92.24 \\
\hline
\end{tabular}

Table 5. Parasitic infestation and anaemic status according to the age group of the adolescent boys of Kutumbopur and Gazirchat areas.

\begin{tabular}{|c|c|c|c|c|c|}
\hline Areas & Age gr. & $\begin{array}{c}\text { No. of boys } \\
\text { examined }\end{array}$ & $\begin{array}{c}\text { Infection } \\
(\%)\end{array}$ & $\begin{array}{c}\text { Boys with } \\
\text { moderate anaemia }\end{array}$ & $\begin{array}{c}\text { Prevalence of anaemia } \\
(\%)\end{array}$ \\
\hline \multirow{6}{*}{ Kutumbopur } & $10-12$ & 40 & 35.00 & 30 & 75.00 \\
\hline & $12-14$ & 8 & 25.00 & 6 & 75.00 \\
\hline & 14-16 & 14 & 28.57 & 6 & 42.86 \\
\hline & $16-18$ & 4 & 0 & 2 & 50.00 \\
\hline & $18-<20$ & 2 & 0 & 2 & 100.00 \\
\hline & $10-<20$ & 68 & & 46 & \\
\hline \multirow{6}{*}{ Gazirchat } & $10-12$ & 22 & 90.90 & 20 & 90.90 \\
\hline & $12-14$ & 12 & 83.33 & 10 & 83.33 \\
\hline & $14-16$ & 4 & 50.00 & 4 & 100.00 \\
\hline & $16-18$ & 0 & 0 & 0 & 0 \\
\hline & $18-<20$ & 0 & 0 & 0 & 0 \\
\hline & $10-<20$ & 38 & & 34 & \\
\hline \multirow{6}{*}{$\begin{array}{l}\text { Kutumbopur + } \\
\text { Gazirchat }\end{array}$} & $10-12$ & 62 & 54.84 & 50 & 80.64 \\
\hline & $12-14$ & 20 & 60.00 & 16 & 80.00 \\
\hline & $14-16$ & 18 & 33.33 & 10 & 55.55 \\
\hline & $16-18$ & 4 & 0 & 2 & 50.00 \\
\hline & $18-<20$ & 2 & 0 & 2 & 100.00 \\
\hline & $10-<20$ & 106 & & 80 & \\
\hline
\end{tabular}


Hyder et al. (1998) found 69\% of male as anaemic in Fullbaria thana of Mymensingh district. Linpisarn (1996) reported that, in Thailand anaemia was common in all age groups with a prevalence of about $25 \%$ in male and $45 \%$ in women and children. Uddin et al. (2005) showed $10.14 \%$ severe anaemia, $69.56 \%$ moderate anaemia and $17.39 \%$ mild anaemia among the adolescent girls of two selected areas of Bangladesh. Uddin, et al. (2005) showed $71.01 \%$ parasitic infection in the adolescent girls of two rural areas and infestation rate was significantly correlated with anaemia. In another study, Huq \& Sheikh (1976) showed the prevalence of parasites as $65.8 \%$. Muttalib (1976) reported the gross prevalence of parasites were $A$. lumbricoides $92.9 \%$, T. trichiura $52.46 \%$, hookworm $9.91 \%$, G. lamblia and E. histolytica $40.88 \%$. Chowdhury \& Brig (1979) investigated intestinal parasitic infections from Dhaka and found $A$. lumbricoides (23.18\%), T. trichiura (10\%), hookworm (6.2\%), E. vermicularis ( $0.28 \%)$ and multiple infections $(10.5 \%)$.

\section{Acknowledgement}

The authors acknowledge the Ministry of Science and Information and Communication Technology under R\&D proposal for financial support under special allocation for Science and Information and Communication Technology for financial year 20022003.

\section{References}

Chowdhury, M. \& Brig, M.R. 1979. Intestinal parasitic infection in privileged class of Dhaka population. Ban. Arm. Med. Jour. 4(1): 5-12.

Gilgen, D. 1998. The effect of iron deficiency anaemia and intestinal helminth infections on labour productivity of adult female tea pluckers. PhD Dissertation, Cambridge, London. pp. 292.

Huq, N. \& Sheikh, A. 1976. Incidence of intestinal parasite in children of different socio-economic population of Dhaka city. B.M.R.C. Bull. 11(1): 20-26.

Hyder, S.M.Z., Chowdhury, S.A. \& Chowdhury, A.M.R. 1998. Prevalence of anaemia and intestinal parasites in a rural community of Bangladesh. BRAC: 43-48.

Karim, M.R., Rahman, M.A. \& Rahman, M.M. 1998. Reflex: A guide to physiology and biochemistry. $8^{\text {th }}$ ed. Shadow printing, Dhaka. pp. 62-108.

Linpisarn, S. 1996. Iron deficiency and anaemia in children with a high prevalence of hemoglobinopathies: implications for screening. Intl. J. Epidemiol. 25(6): 1262-1266.

Muttalib, M.A. 1976. Prevalence of intestinal parasite in rural children in Bangladesh. Bang. Med. J. 4(1): 15-21.

Uddin, M.H., Rahman, M.M. \& Khanum, H. 2005. Hemoglobin level among adolescent girls and it's relation to intestinal parasites. Bangladesh J. Zool. 33(2): 183-187.

World Health Organization. 1992. The prevalence of anaemia in women: a tabulation of available information. $2^{\text {nd }} \mathrm{Ed}$. Geneva, WHO: 5-12.

World Health Organization. 1994. Report of the WHO informal consultation on hookworm infection and anaemia in girls and women. WHO/CTD/SIP/96. 1: 1-46.

Manuscript received on 25.05.-2008, accepted on 06.09.2008 